\title{
A Review of Masonry Buckling Characteristics
}

\author{
Mir Abdul Kuddus ${ }^{1}$, Pere Roca Fabregat ${ }^{2}$ \\ ${ }^{1}$ Assistant Professor, Department of Civil Engineering, Khulna University of Engineering \& Technology, \\ Khulna-9203, Bangladesh, \\ ${ }^{2}$ Professor, Department of Civil and Construction Engineering, Technical University of Catalonia, Barcelona- \\ 08034, Spain.
}

\begin{abstract}
Masonry load bearing wall subjected to vertical concentric and eccentric loading may collapse through instability. In this Paper the buckling behaviour of masonry load bearing wall of different slenderness ratio were investigated by many researcher has been reviewed via testing a series of scale masonry wall subjected to concentric and eccentric vertical loading. It is also observed that buckling behaviour is greatly influenced by the material properties of units, mortar and units-mortar interface. The influence of nonlinear behaviour of interface element, slenderness ratio and various end conditions have been investigated together with the effect of different end eccentricity of vertical load.
\end{abstract}

Keywords: Masonry load bearing wall, buckling failu re, eccentric load, slenderness ratio.

\section{INTRODUCTION}

Load bearing masonry is among the most ancient architectural technologies, yet continues to provide boundless opportunities for both traditional and modern design. Historically, the structural design of masonry buildings was based on the empirical requirements of building codes for minimum wall thickness and maximum height. Bearing wall construction for buildings higher than three to five stories was uneconomical and other methods of support (steel or concrete skeleton frame) were generally used. In 1965, there was a renewed interest on the part of the design professional, architect and engineer, in modern bearing wall construction, wherein the design is based on a rational structural analysis rather than on outmoded arbitrary requirements. Many research projects have been conducted on the properties of the three basic components and the overall unreinforced masonry wall with vertical load and load eccentricities. The literature on the subject shows large number of studies carried out on axially loaded walls with varying slenderness ratio. Among the first, Chapman and Slatford (1957) obtained closed form solutions for the load deformation behaviour of brittle elastic wall by assuming that masonry material has no tensile strength and that cracking occurs whenever a tensile stress would develop. After that Yokel's (1971) results on the buckling of walls made of notension material are well known. De Falco's proposal (2002) on the stability of columns using an elastic-plastic material model stands among the most recently presented analytical approaches. More recently, Mura (2008) has utilized a parabolic stress-strain relationship to describe the behaviour of the brickwork under compression loads. Shalin (1978) reviewed the results of analysis carried out by a number of authors and presented experimental evidence in support of the calculations. Further work was carried out by Sawko and Towler (1982) who proposed a numerical procedure for calculating the failure load of a no-tension material wall. An analytical solution has been carried out by Romano et al. (1993), considering no tension bearing masonry with a monomial stress-strain relationship in compression. Parland et al. (1982) proposed a method for determining buckling failure load of a slender wall, taking into account the effect of tension stress field which exists between the cracked joints. However, the linear elastic materials were used in this analysis.

\subsection{Masonry Materials and Properties}

A close-up view of a typical masonry wall is shown in Figure 1. Masonry is a composite construction material consisting of masonry units and mortars built following certain pattern. The mechanical properties of masonry vary considerably due to variable material properties of units and mortars. For example, mortar is typically composed of cement, lime, sand and enough water to produce a plastic, workable mixture. Several different types of mortars have been widely used in the construction, as shown in Table 1 (ASTM 1958). 


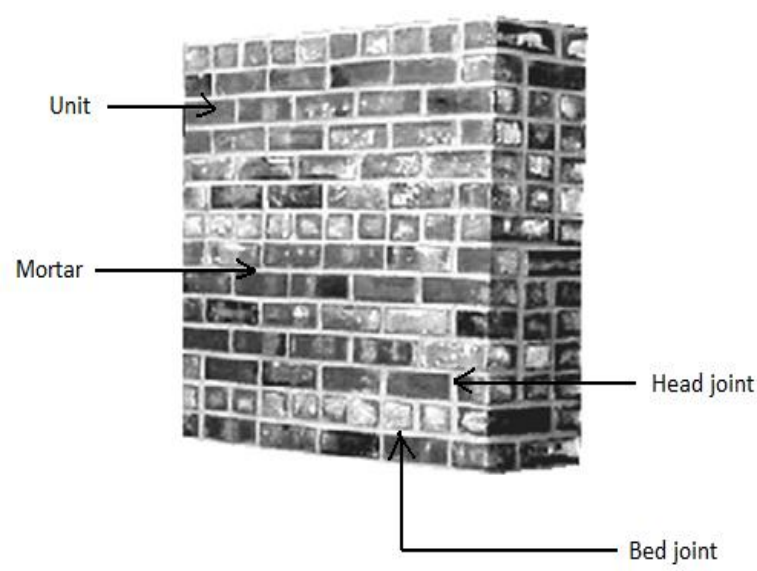

Figure 1: Typical masonry wall.

Table 1: Mortar compositions by volumes.

\begin{tabular}{|l|l|l|}
\hline Type & $\begin{array}{l}\text { Ratio (cement: } \\
\text { lime: sand) }\end{array}$ & $\begin{array}{l}\text { Compressive } \\
\text { strength( psi) }\end{array}$ \\
\hline $\mathrm{M}$ & $1: 0: 3$ & 2500 \\
\hline $\mathrm{S}$ & $0.5-1: 0.25-0.5: 4.5$ & 1800 \\
\hline $\mathrm{N}$ & $1: 0.5-1.25: 6$ & 750 \\
\hline $\mathrm{O}$ & $1: 2: 9$ & 350 \\
\hline $\mathrm{K}$ & $0.5: 2: 7.5$ & 75 \\
\hline
\end{tabular}

* No longer used in construction after 1960's

Brick, concrete masonry units, clay tile, and stone have all been used for the masonry units in previous practice. Brick masonry is the focus of this research, because it makes up majority of the existing unreinforced masonry buildings.

The mechanical properties of masonry as a composite material are functions primarily of the mechanical properties of the individual masonry units, mortars, and the bond characteristics between units and mortar. Strictly speaking, unreinforced masonry construction results in an anisotropic material. However, for a simplified design approach, the elastic properties of masonry materials are usually considered as is otropic. These elastic, isotropic properties are taken as those determined from tests on masonry pris ms perpendicular to the bed joints. The elastic modulus of masonry is controlled by the combined elastic modulus of masonry units and mortar (Hamid et al. 1987). Previous research indicates a large scatter in the measured elastic modulus of masonry. Two reasons explain the large scatter. First, the material properties of masonry units and mortar vary significantly by themselves. Second, different workmanship factors may contribute to the variation as well. The European code (EC6 1995) gives the following formulae for calculating Young's modulus E and shear modulus $G$ of masonry material for a design purpose:

$$
E=1000 f_{m} ; G=0.4 E
$$

Where, $f_{m}$ is the characteristic compressive strength of masonry. Some other researchers recognized that masonry is actually a nonlinear material and thus its elastic modulus varies with different stress level. Experimental stress-strain relationship of mortar, brick, masonry prism and masonry panel is shown in the Figure 2. Usually the compressive strength of the masonry falls in between compressive strength of bricks and mortar.

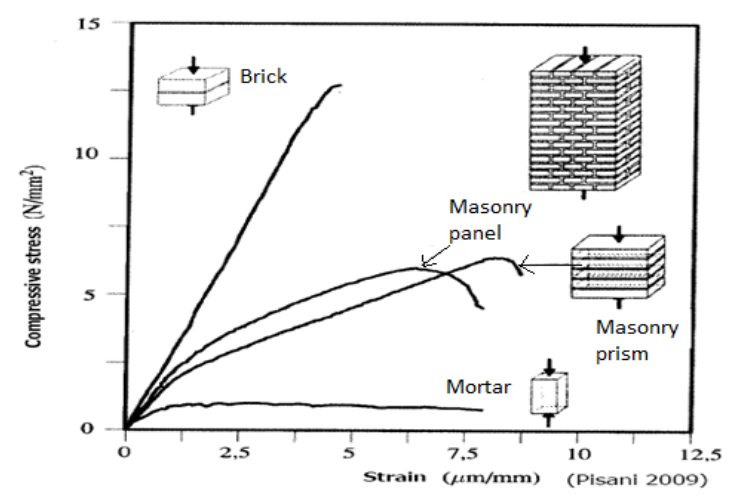

Figure 2: Typical stress-strain diagram of masonry components.

Compressive strength tests are easy to perform and give a good indication of the general quality of materials used. The CEN Eurocode 6 (1995) uses the compressive strength of the components to determine the strength of masonry even if a true indication of those values is not simple. For masonry units, standard tests with solid platens result in an artificial compressive strength due to the restraint effect of the platens. The CEN Eurocode 6 (1995) minimizes this effect by considering a normalized compressive strength $f_{b}$, that result from the standard compressive strength in the relevant direction of loading multiplied by an appropriate size or shape factor. The normalized compressive strength refers to a cube specimen with $100 \times 100 \times 100\left(\mathrm{~mm}^{3}\right)$ and cannot be considered representative of the true strength. The normalized compressive strength of unit is calculated according to Eurocode $6: \mathrm{f}_{\mathrm{b}}=\mathrm{f}_{\mathrm{b}, \mathrm{m}} * \delta$, where $\delta$ =shape coefficient. The compressive strength test for masonry unit is shown in Figure 3.
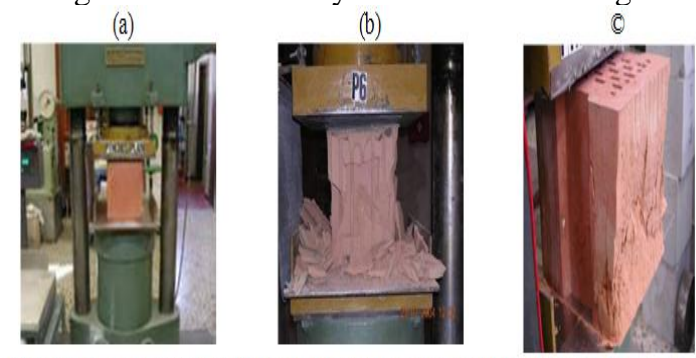

Figure 3: Test of masonry units (da Porto 2003) (a) test setup (b) and (c) specimen after test. 
It is difficult to relate the tensile strength of the masonry unit to its compressive strength due to the different shapes, materials, manufacture processes and volume of perforations. For the longitudinal tensile strength of clay, calciumsilicate and concrete units, Schubert (1988a) carried out an extensive testing program and obtained a ratio between the tensile and compressive strength that ranges from 0.03 to 0.10 . For the fracture energy $G_{f}$ of solid clay and calcium-silicate units, both in the longitudinal and normal directions, Van der Pluijm (1992) found values ranging from 0.06 to $0.13\left(\mathrm{Nmm} / \mathrm{mm}^{2}\right)$ for tensile strength values ranging from 1.5 to 3.5 $\left(\mathrm{N} / \mathrm{mm}^{2}\right)$.

Currently, investigations in mortar disks extracted from the masonry joints are being carried out to fully characterize the mortar behavior, Schubert and Hoffman (1994). Nevertheless, there is still a lack of knowledge about the complete mortar uniaxial behavior, both in compression and tension.

The nonlinear properties of masonry, such as ultimate strength and ductility, are also directiondepended.

\subsection{Buckling and Material Overstressing}

Any compression member usually fails both due to the buckling and material overstressing. The more slender the member the greater the possibility to buckling failure; the more squat the member the greater propensity to material overstressing. The combination of buckling failure mode with the mode of ultimate material failure is shown in the Figure 4. The figure shows that with the increasing of both slenderness ratio and reduction factor the paossibility of buckling failure increases. The material failure occurs in the case of low slenderness ratio with high reduction factor. In addition, buckling failure connect with material failure where the members may fail due to combination of both mechanisms. High slenderness ratio andlow reduction factors indicate general buckling when low slenderness ratio and high reduction factors produce Euler buckling.

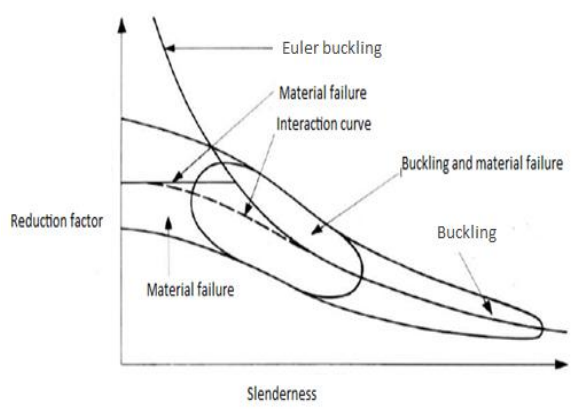

Figure 4: Buckling and material overstressing interaction curve (Morton, 1990).
The mathematical solution for the differential equation describing a perfectly idealized strut was proposed by Euler as:

$$
P_{c}=\pi^{2} \frac{E I}{L_{e}{ }^{2}}
$$

Writing this formula in terms of critical stress:

$\sigma_{E}=\frac{P_{c}}{A}=\frac{\pi^{2}}{A} \frac{E I}{L_{e}{ }^{2}}$

$\sigma_{E}=\pi^{2} E /\left(L_{e} / r\right)^{2}$

Where,

$r$ radius of gyration;

$P_{c} \quad$ Euler critical load;

$L_{e} \quad$ effective length (or height) of me mber;

$E \quad$ elastic modulus of masonry;

$I$ second moment of area of section;

A area of section.

The material strength properties have been rigoriously investigated and BS 5628 contains table of characteristic strength $f_{k}$ for the various masonry formats. In general:

$P_{w l t}=\sigma_{w l t}$

and for wall construction the maximu $\mathrm{m}$ stress:

$\sigma_{u l t}=f_{k}$

The above model is based on the basic Rankine approach of having a straight line joining the two axes ( see Figure 5):

$\frac{1}{P}=\frac{1}{P_{\text {material failure }}} \frac{1}{P_{\text {bwekling failure }}}$

Presenting this in terms of stresses:

$\frac{\sigma}{\sigma_{\text {ult }}}=1-\frac{\sigma}{\sigma_{E}}$

Where,

$P_{\text {wlt }}$ ultimate load for material strength failure;

$\sigma_{\text {ult }}$ ultimate stress for material strength failure;

$\sigma_{E} \quad$ Eu ler critical stress.

This is a emperical relationship between the elastic modulus of masonry, $\mathrm{E}$ and the compressive strength of the masonry. This is incorporated in BS 5628: part 2 as $900 \mathrm{f}_{\mathrm{k}}$ (MPa) for the short term modulus of elasticity of clay, calcium silicate and concrete masonry. Again, according to Eurocode 6, this relation is consideed as $1000 \mathrm{f}_{\mathrm{k}}(\mathrm{MPa})$. 


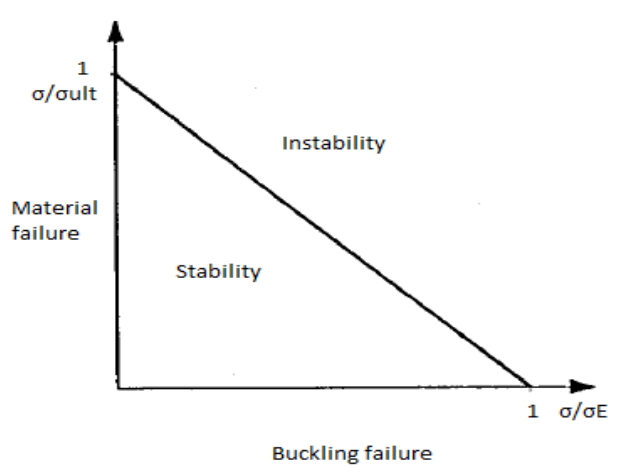

Figure 5: Combining buckling with material overstressing of masonry.

\subsection{Concentric Loading Wall}

The brickwork has a number of peculiarities that make the different development. This exposed several problems and observations. In this section Masonry walls with vertical load which applied without any eccentricity is described. Previous sections have presented the expression for the Eu ler critical buckling load in wall under centered load. This expression is valid in the case of composite parts of a material elastic follow the Hooke's law.

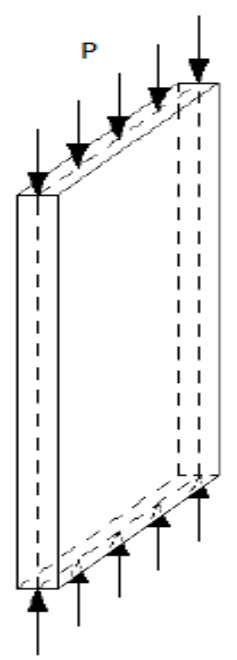

Figure 6: Concentrically loaded wall.

In this case, the stresses are evenly distributed, with the stress instability:

$$
\sigma_{c r}=\frac{P_{c r}}{A}=E\left(\pi \cdot \frac{i}{h}\right)^{2}
$$

Where,

A cross sectional area;

E modulus of elasticity;

$\mathrm{i}=\sqrt{\frac{I}{A}}$ radius of gyration;

h height of the wall.

In the case of brickwork, this expression becomes invalid because the material not satisfies Hooke's law, means no linear proportionality between stress and strain. For this situation the formula derived by Ritter (quoted by Knutsson, 1991) is introduces:

$E=E_{0}\left(1-\frac{\sigma}{f_{c}}\right)$

With,

E tangent modulus of elasticity for small strains;

$\mathrm{f}_{\mathrm{c}} \quad$ compressive strength.

Introducing this value of $\mathrm{E}$ in the expression 9 gives:

$\sigma_{c r}=E_{0}\left(1-\frac{\sigma_{c r}}{f_{c}}\right)\left(\pi \cdot \frac{i}{h}\right)^{2}$

Can be expressed as:

$\sigma_{c r}=\frac{P_{c r}}{A}=\frac{f_{c}}{1+\frac{f_{c}}{\pi^{2} \cdot E_{0}}\left(\frac{h}{i}\right)^{2}}$

This expression is commonly known as Ritter's formula, is used as the Rankine, Grashof, Engesser Winkler or have been associated with it (Knutsson, 1991).

\subsection{Eccentric Loading Wall}

Ritter's formula shown above is valid for masonry walls subjected to centered load. In a real case, it is common to find situations where the loads are applied eccentric.

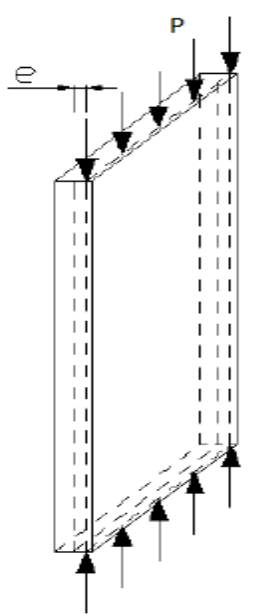

Figure 7: Eccentrically loaded wall.

In these cases, a simplification can make by assuming a symmetrical stress distribution around the load and neglecting the part of the section outside of the distribution. With this simplification, the bearing capacity of the structure can be calculated as a structure with load centered and with a thickness equal to (Figure 8):

$2\left(\frac{t}{2}-e\right)=(t-2 e)$

Where,

$\mathrm{t}$ total thickness of the wall; and 
e eccentricity with which the load is applied.

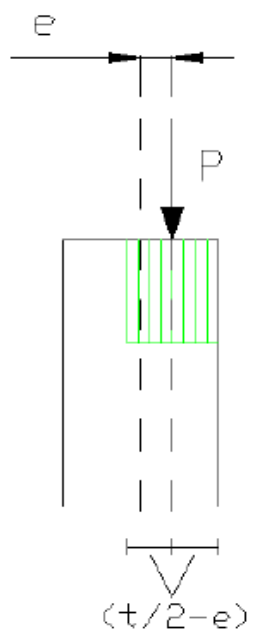

Figure 8: Simplification consists in assuming a symmetrical stress distribution around load.

Therefore, the critical stress can be calculated as:

$$
\sigma_{c r}=\frac{P_{c r}}{A_{c}}=\frac{f_{c}}{1+\frac{f_{c}}{\pi^{2} \cdot E_{0}}\left(\frac{h}{i_{c}}\right)^{2}}
$$

Where,

$\mathrm{A}_{\mathrm{c}} \quad$ compressed cross-sectional area considering the new equivalent thickness;

$\mathrm{I}_{\mathrm{c}}=\sqrt{\frac{I}{\mathrm{~A}_{\mathrm{c}}}}$, radius of gyration of the compressed section.

The latter term is more general and applies to both load cases centered (in which eccentricity is null and the compressed area is the total area of the section) and the case of load eccentrically applied.

Resistance may be affected by the fact that on the surface of the masonry mortar is not confined, being the weaker joints near the surface. This may be especially critical for walls with a reduced thickness. In order to consider this effect, Knutsson (1991) proposed the stress reduction by a coeffic ient $\mathrm{k}_{\mathrm{t}}$.

$\mathrm{K}_{\mathrm{t}}=0.8$ for walls with $90<\mathrm{t} \leq 125 \mathrm{~mm}$

$\mathrm{K}_{\mathrm{t}}=0.9$ for walls with $125<\mathrm{t} \leq 175 \mathrm{~mm}$

$\mathrm{K}_{\mathrm{t}}=1$ for walls with $\mathrm{t}>175 \mathrm{~mm}$

As explained above, the critical load is determined as:

$$
P_{c r}=K_{t} \sigma_{c r} A_{c}=K_{t} \frac{f_{c}}{1+\frac{f_{c}}{\pi^{2} E_{0}}\left(\frac{h}{i_{c}}\right)^{2}} A_{c}
$$

Can be expressed in abbreviated form as:

$$
P_{c r}=K_{t} K_{s} A_{c} f_{c}
$$

Where,

$$
\begin{aligned}
K_{s} & =\frac{1}{1+\frac{1}{\pi^{2} K_{r}}\left(\frac{h}{i_{c}}\right)^{2}} ; \\
K_{r} & =\frac{E_{0}}{f_{c}} \text { Ritter constant for the material. }
\end{aligned}
$$

The expression obtained can be particularized for the case of rectangular sections, which is:

$P_{c r}=K_{t} K_{s}(t-2 e) l f_{c}$

With,

$$
\begin{aligned}
K_{s}= & \frac{1}{1+\frac{12}{\pi^{2} K_{r}}\left(\frac{h}{t-2 e}\right)^{2}} \\
& \quad \begin{array}{l}
\text { total width of the wall; } \\
\mathrm{t}
\end{array} \\
\mathrm{e} & \text { thickness of the wall; and } \\
& \text { eccentricity of load application. }
\end{aligned}
$$

When the load is applied on a solid wall with an eccentricity greater than $t / 6$, the wall develops tension within a certain zone. The zone is shown in Figure 9. It is assumed that this portion of the wall cracks slightly at each joint, in compliance with the assumption of a no tension material. The geometry of the cracked section changes for different values of eccentricity of load application. It is therefore necessary to apply the principles of the basic approach to the remaining uncracked portion of the wall.

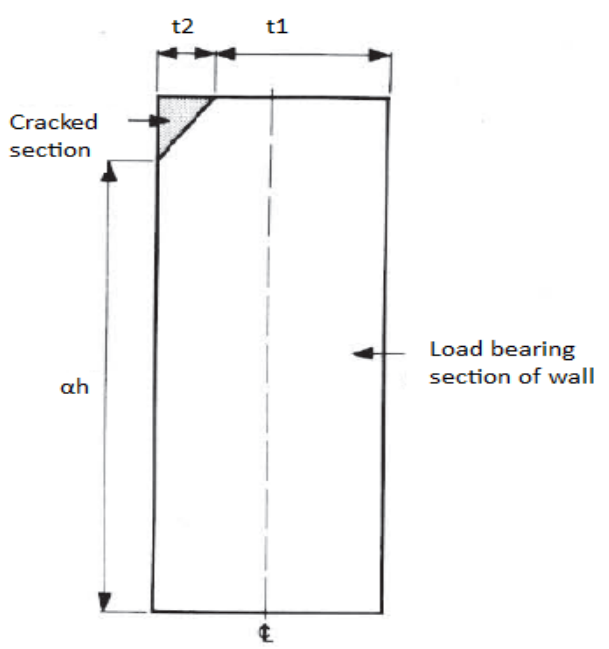

Figure 9: Tension zone in a solid eccentrically loaded wall.

Figure 10 shows, schematically, the effect of increasing eccentricity ratio on the size of the wedge shaped cracked section. The position of the maximum deflection rises progressively above the mid-height of the wall. In addition, the critical load of the wall is progressively reduced as the area of the tapered portion of the wall becomes smaller. 


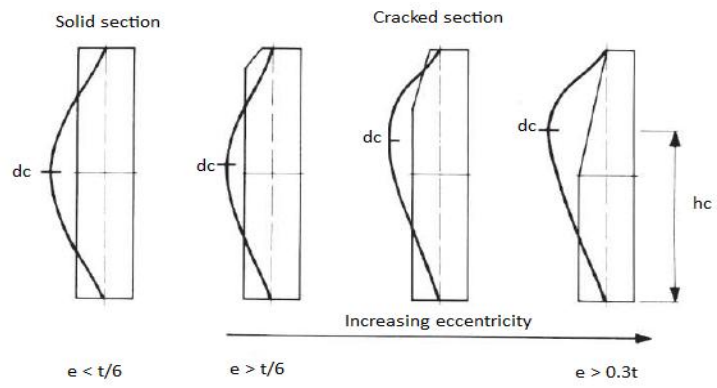

Figure 10: Effect of increasing eccentricity on the size of cracked section.

An important aspect is that for the range of applied eccentricity (at the top of the wall) $t / 6<$ $\mathrm{e} \leq 0.3 \mathrm{t}$ the width of the section at a critical section remains $t$. When e $>0.3 \mathrm{t}$ the size of the wedge shaped cracked section intrudes through the critical section and its thickness is less than wall thickness, t.

\subsection{Effects of Slenderness Ratio and Eccentricity of Loading}

The modern masonry wall constructions allow slenderness of the wall and the eccentricity of vertical loading by the application of a reduction factor to the masonry strength. In traditional construction usually the load bearing walls are relatively thick and if the ratio of height to thickness is no more than about 10 , the effect of slenderness will be negligible. DIN 1053 limits the slenderness ratio to 20 and permits only the two better quality grades between 10 and 20 . In this range the material strength is to be reduced by a factor $(25-\mathrm{h} / \mathrm{t}) / 15$ and only light loading is permitted on walls having a slenderness ratio over 14. On the other hand, the Eurocode- 6 limits the slenderness ratio for masonry wall to 27 . Within this constraint Hendry (1976) calculated maximum stresses due to eccentric loading by using conventional linear theory. The maximum compressive should not exceed the material strength divided by an appropriate safety factor. No tensile strength is assumed in this case.

The effect of slenderness ratio and eccentricity on the compressive strength of walls was investigated by Hasan and Hendry (1976), to determine whether reduction factors prescribed in various codes are conservatives. One third scale model has been tested with axial and eccentric loading and with various end conditions.

The results were compared with various national codes. Twenty five specimens were tested in different end conditions such as flat ended, reinforced concrete slab and hinged with different load eccentricity. The walls were constructed by using stretcher course and English bond. Results found in this test shows decrease in strength of walls of flat ended with the increase in slenderness ratio except of wall of slenderness ratio 12 . In all walls except hinge supported series, the first hairline crack appeared between $50-60 \%$ of failure load and enlarged with further increase of load. The general mode of failure of the walls was vertical splitting accompanied by crushing and splitting of various courses of bricks. However, in walls of slenderness ratio 25 and all walls of vertical load eccentricity $t / 3$ group failure occurred at mortar brick interface due to breakdown of bond between the mortar and the brick at the time of maximum deflection.

\subsection{Influence of Tensile strength on Masonry Wall Stability}

The influence of tensile strength on the stability of masonry wall was investigated by Schultz and Bean, a sample cantilever masonry wall is used to demonstrate the sensitivity of critical axial loads on masonry tensile strength. The wall, the profile of which is shown in Figure 11, is subjected to a concentrated eccentric vertical load $P$, a concentrated horizontal top load $Q$, a distributed horizontal load $q$, and weight $W$, distributed along wall height. The wall is subdivided into $N$ ele ments of equal length.

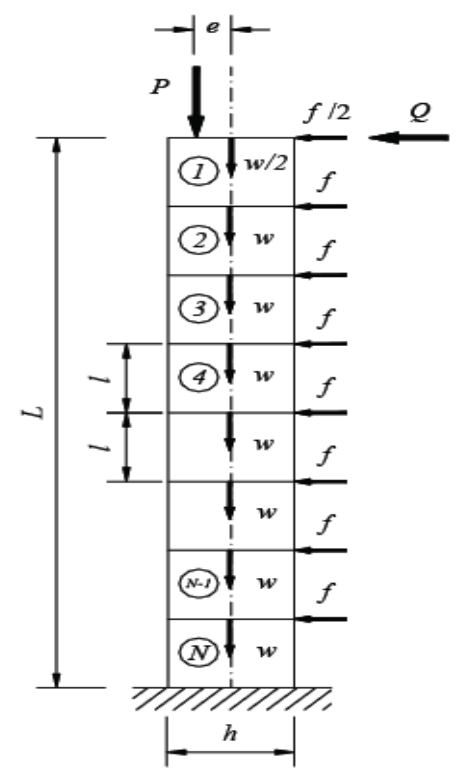

Figure 11: Idealized masonry wall (Schultzet al, 2009).

The distributed loads, namely weight $W$ and lateral load $q$ are converted to concentrated nodal loads (i.e., $w=W / N$ and $f=q L / N$ ). The height of the masonry wall is $L=6 \mathrm{~m}(19.7 \mathrm{ft})$, and the thickness is $h=200 \mathrm{~mm}$ (7.9 in.). The mechanical properties are $\varepsilon_{c u}=0.005, E=125.9$ $\mathrm{N} / \mathrm{mm}^{2}(2.900 \mathrm{ksi})$ and $v=0.17$. Moreover, the 
concentrated lateral load $Q$ the distributed lateral load $q$ and the self weight $W$ are assumed to be proportional to vertical load, and are represented by normalized variables $q L 2 / 2 P h, Q L / P h, W / P$, and $e / h$. Figure 12 shows the axial load vs. lateral deflection $(P-\Delta)$ curves for various values of the parameter $100 \varepsilon c r / \varepsilon_{c u}$. The case of a masonry wall with no tensile strength, which has been studied by many researchers, corresponds to $100 \varepsilon c r / \varepsilon_{c u}=0$, whereas the maximum value for the tensile capacity parameter, i.e., $100 \varepsilon c r / \varepsilon_{c u}=2$, represents a practical upper bound for contemporary masonry materials.

Cracking strength is seen to have a remarkable impact on the shape and smoothness of the stability curves, but it does not have much influence on the values for ultimate tip deflection, i.e., when load capacity vanishes $(P=0)$. However, tensile strength does have an effect on tip deflection values corresponding to the critical (peak) axial load (Figure 12). The peak value for vertical load (i.e., the critical axial load $P_{c r}$ ) was taken for each of the $P-\Delta$ curves that were generated for a specific tensile strength $\left(100 \varepsilon_{c r}\right.$ $\left./ \varepsilon_{c u}\right)$. The resulting relationship is shown in Figure 13, which produces the dramatic influence in critical axial load capacity $P_{c r}$ with increasing tensile strength, $100 \varepsilon_{c r} / \varepsilon_{c u}$.

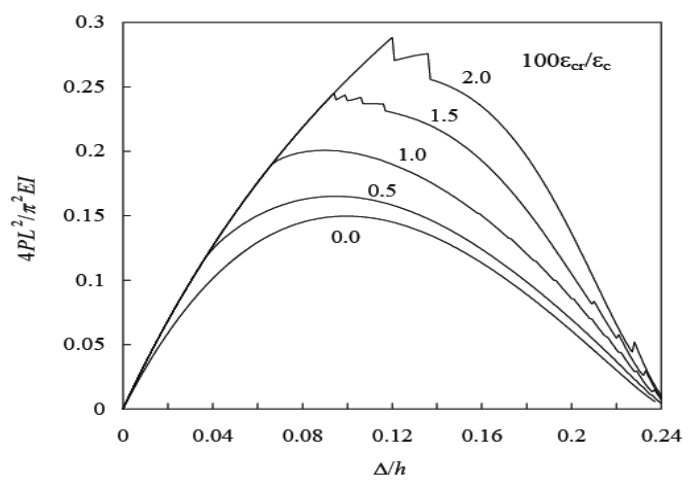

Figure 12: Influence of tensile strength on load deflection behavior (Schultz et al, 2009).

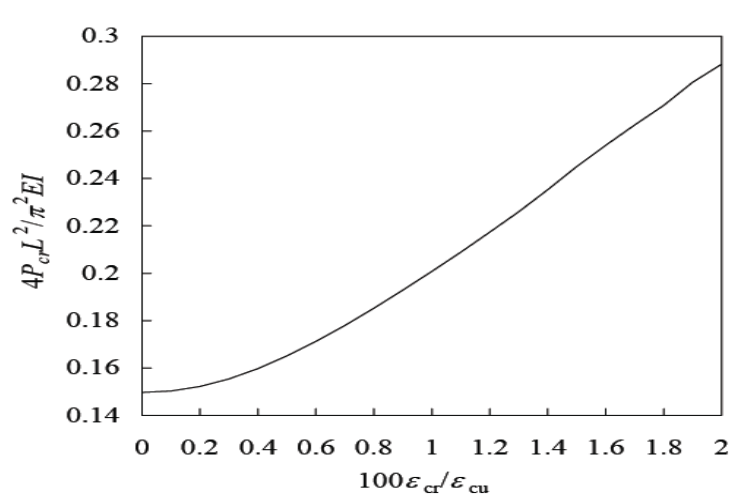

Figure 13: Influence of tensile strength on axial critical load (Schultz et al, 2009).

The same wall configuration was analyzed for increasing eccentricity, $e$, of vertical load $P$ but with no lateral loading (i.e., $Q=q=0$ ). Critical axial load, as function of eccentricity, is shown in Figure 14, which demonstrates the importance of this parameter on buckling capacity. As e/h increases from 0 to 0.5 , buckling capacity for eccentrically compressed walls decreases by a factor of 5. However, current US code provisions assume that the buckling capacity of eccentrically compressed masonry walls vanishes as eccentricity $e$ approaches one-half of the wall thickness $h$.

In the many research the buckling capacities of masonry walls were computed, but only for the case of no tensile strength (i.e., $100 \varepsilon_{c r}$ $\left./ \varepsilon_{c u}=0\right)$. Even modest tensile capacities in masonry give rise to finite buckling strengths, even for cases where $e / h>0.5$, as noted by the horizontally asymptotic behavior of the curves shown in Figure 14. The $P_{c r}$ vs. $\varepsilon_{c r} / \varepsilon_{c u}$ curves shown in Figure 14 indicate that increases in buckling capacity with tensile strength are substantial only for walls with large eccentricity (i.e., $e / h>0.2$ ).

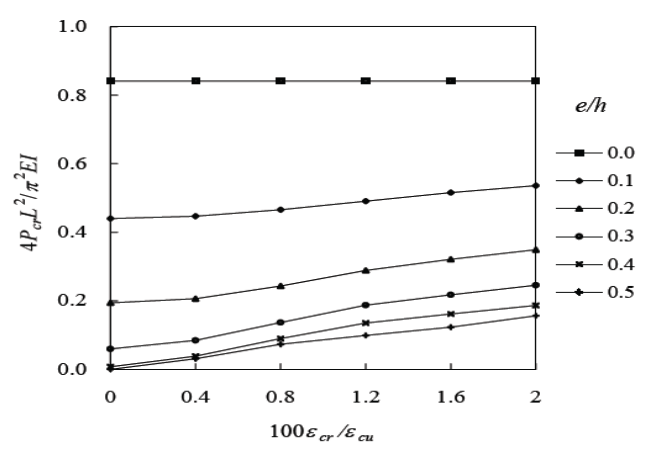

Figure 14: Influence of tensile strength on the buckling capacity of eccentrically loaded wall (Schultz et al, 2009).

\subsection{Analytical and Numerical Approaches}

Yokel (1971) developed an analytical formula to determine the critical load of pris matic elements that, because of a very low tensile 
strength, have cracked sections. The study was based on a prismatic rectangular section, consisting of an elastic material, with a linear relationship between stress and strain and did not develop resistance to traction (Figure 15, left). The loading conditions considered by Yokel (1971) consisted of a load $\mathrm{P}$ acting direction parallel to the axis of the piece, applied with an eccentricity value $\mathrm{t} / 2>\mathrm{e} \geq$ t/6. The piece considered hinged at both ends, so that the rotation was not restricted (Figure 15, right). The balance in any section requires that the reaction is equal to the applied load. The resulting stress distribution of a section is shown in the Figure 16.

Figure 16 (a) shows the case where the load $\mathrm{P}$ acts at an eccentricity equal to kern eccentricity $(e=t /)$. In the case the compressive stresses at one face (the tension face) of the cross section is zero. At the other face the maximum compressive stress occurs. The value of the maximu $m$ stress produced is:

$\sigma_{0}=\frac{2 P}{b t}$
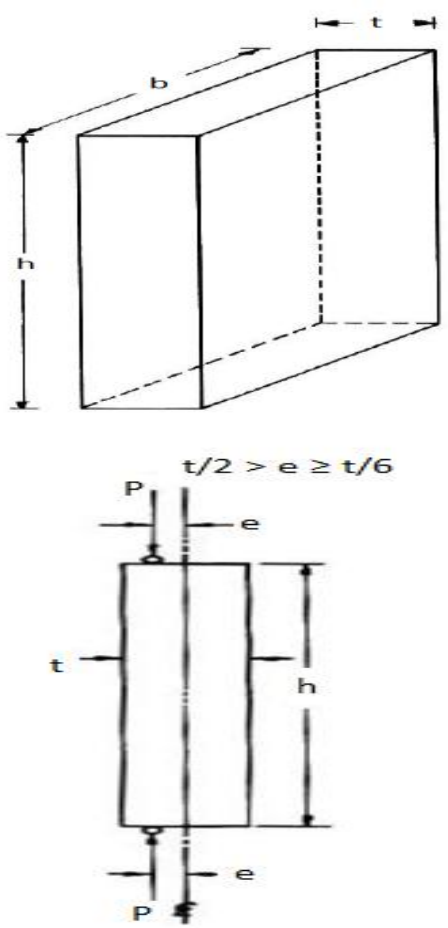

Figure 15: The dimension of wall (left) and loading condition (right).

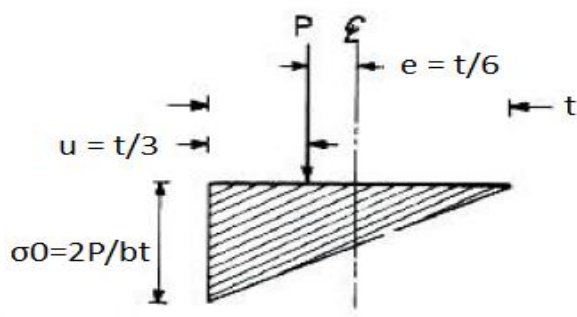

(a) $\mathrm{e}=\mathrm{t} / 6$

Figure 16: Resulting stress distribution (a) corres ponds to an eccentricity $\mathrm{t} / 6$ (b) corres ponds to an eccentricity greater than $\mathrm{t} / 6$.

In the figure 16 (b) the load $\mathrm{P}$ acts at a higher eccentricity $t / 6$, i.e. the load is applied outside the kern of the section. The maximum stress at compression face of the cross section is:

$\sigma_{0}=\frac{2 P}{3 b u}$

Where, $\mathrm{u}$ is the distance between the line of application of $\mathrm{P}$ and compression face of section the cross section, $\mathrm{P}$ is the compressive force applied to me mber and $\mathrm{b}$ is the width of member.

On the other hand, a tensile crack appears at the tension side of the cross section, as the material has no tensile strength. The uncracked part

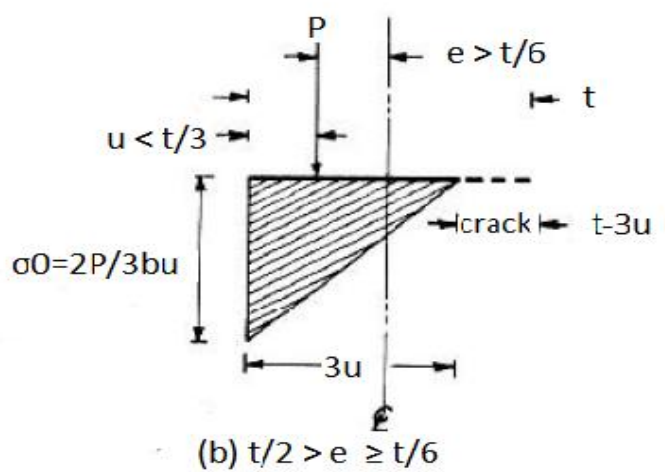

of the cross section has a triangular stress distribution similar to that shown in figure 16 (a), where $\sigma=0$ at the origin of crack. The uncracked thickness of the section is $3 u$ and depth of cracks is therefore $\mathrm{t}-3 \mathrm{u}$. The expression 18 is valid for all cases in which the values of eccentricity are $t / 2>\mathrm{e}$ $\geq t / 6$. Stress distribution within the entire wall is shown in Figure 17. 


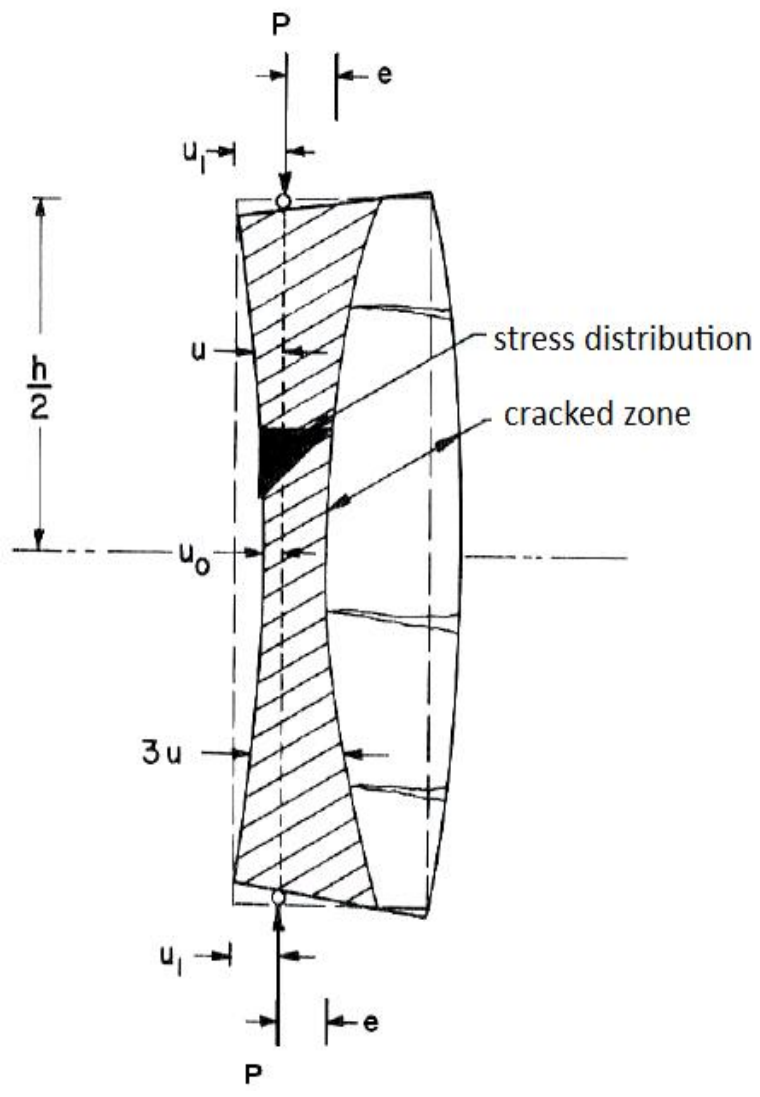
of the wall.

Figure 17: Stress distribution in the units

The rectangle obtained by broken lines shows the undeflected shape of the member. The deflected shape is shown by the heavy out line. The shaded area within the deflected member shows the un-cracked zone which supports the load. The stress distribution at one particular cross section is shown by the heavy-shaded triangle.

Distance, $\mathrm{u}$ between the compression face of the member and the line of action of force $P$ varies along the height of the member because of member deflection. The maximum distance $\mathrm{u}_{1}$ occurs at the two member ends. The minimum distance $\mathrm{u}_{0}$ occurs at mid-height. The maximum compressive stress in the member occurs at midheight is:

$$
\sigma_{\max }=\frac{2 P}{3 b u_{0}}
$$

Figure 18 shows the deflection curve of the compression face of the member, together with the coordinate systemused. The $\mathrm{x}$ axis is parallel to the action line of $\mathrm{P}$ and is tangential to the deflection curve at the origin. At each point, $y=u-u_{0}$ and at $\mathrm{x}=\mathrm{h} / 2, \mathrm{y}=\mathrm{u}_{1}-\mathrm{u}_{0}$.

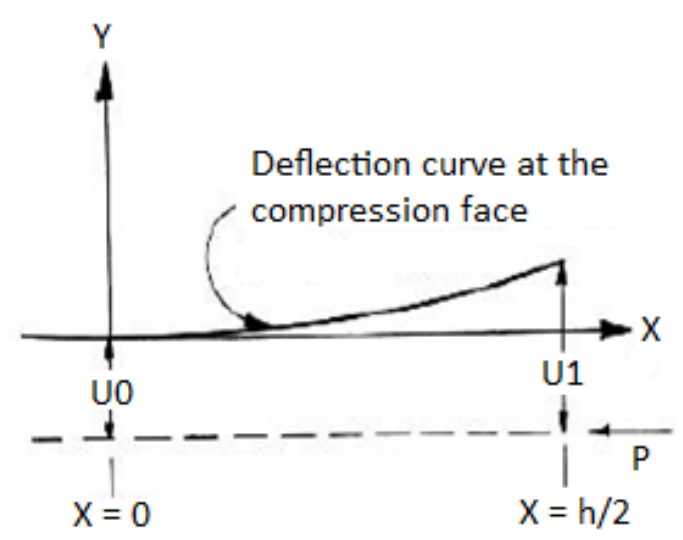

Figure 18: Deflection curve of compression face.

By this approach, finally the equivalent critical load is computed from an equivalent moment of inertia and based on an equivalent thickness of $3 u_{1}$ is:

$$
P_{\text {eec }}=\frac{9}{4} \frac{E b u_{1}^{3}}{h^{2}}
$$

Where,

$P_{\text {eec }}$ equivalent critical load;

$u_{1}$ distance between line of action of compressive load and compression face of member at me mber support.

Note that, $P_{\text {eac }}$ becomes the Euler load, when the section is loaded at the edge of the kern $\left(3 \mathrm{u}_{1}=\mathrm{t}\right)$ i.e. the load is applied at an eccentricity equal to t/6.

Yokel concluded that the elastic instability is given for the value of good crit icis $\mathrm{m}$ :

$P_{c r}=0.285 P_{\text {eec }}$

Where, $P_{c r}$ is the critical load of me mber.

Substituting the value of $P_{\text {e日C }}$ in the expression and obtained:

$P_{c r}=0.64 \frac{E b u_{1}{ }^{3}}{h^{2}}$

The author observed the expressions obtained by comparing with the results of a pilot scale test conducted by the Institute of Structural Clay Products. The test included slenderness ratio of 6.6 to 46.1 and the eccentricities $t / 6$ to $t / 3$.

In this comparison the author obtained the following conclusions:

- The masonry tested developed a tensile strength of around $2 \%-3 \%$ of compressive strength. This change translates into greater capabilities than those obtained by author's formulation. These differences will be greater for situations where failure occurs at relatively low stress (high ratio of slenderness and eccentricity). 
- The stress - strain curve for bricks is not exactly linear. The tangent modulus of elasticity at failure tends to be about $70 \%$ of initial value. If deflections are predicted on the basis of modulus of elasticity at low stress levels, deflections at high stress levels would probably be greater than the predicted deflections. This effect is more pronounced for reasons of slenderness and low eccentricity.

- The brick units themselves have greater strength and stiffness than the mortar beds connecting the units. This discontinuity stress distribution causes a much more complex than the idealized distribution assumed by the author for the solution. The author did not evaluate the effect of these discontinuities on strength and stiffness.

A numerical model for the analysis of structural members under eccentric compression is presented by Vassilev et al. (2009). The equilibrium is formulated in the deformed state and takes account of the effect of deflections on the bearing capacity. The assumed parabolic stressstrain function allows a realistic modeling of the composite material behavior in compression and bending. Due to the physical and structural nonlinearities, the bending stiffness becomes under loading a function of the stress state, thus leading to variable coefficients of the governing differential equation.

The system solution is obtained within an iterative numeric procedure, based on the discretisation of the structure into finite segments and the piecewise linearization of its parameters. The piecewise integration of the equilibrium differential equation leads to a formulation in terms of the transfer matrix method. The ultimate state is marked either by equilibrium bifurcation and loss of stability or collapse due to material failure. The performance of structural members under eccentric compression is usually assessed through the equilibrium conditions of models like the one on Figure 19. The bearing capacity is ensured as long as the resistance can equal the compressive and bending action of the external load. At ultimate level the capacity is exhausted either due to material failure or excessive increase of deflections leading to loss of stability.
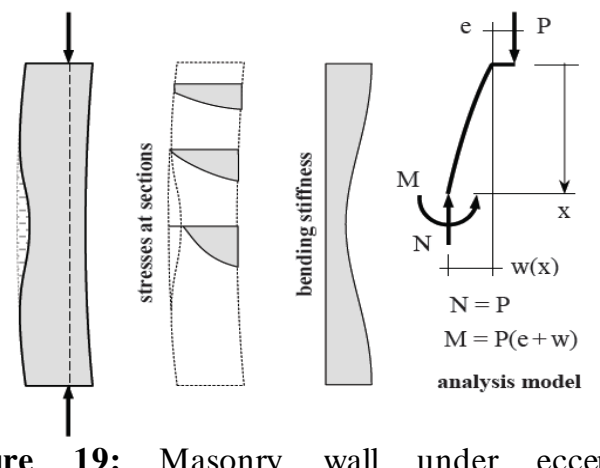

Figure 19: Masonry wall under eccentric compression (Vassilev et al. 2009).

If the bending stiffness $B$ and the compressive force $\mathrm{N}$ remain constant over the height, then the problem has an explicit solution, based on the familiar differential equation:

$B w^{m}+P(w+e)=0$

The basic steps of the iterative procedure are presented in Figure 20. An update of the stepped stiffness function serves as starting point for each iteration. The first step of the analysis procedure under a prescribed load level is the System Solution which is based on the transfer matrix method.

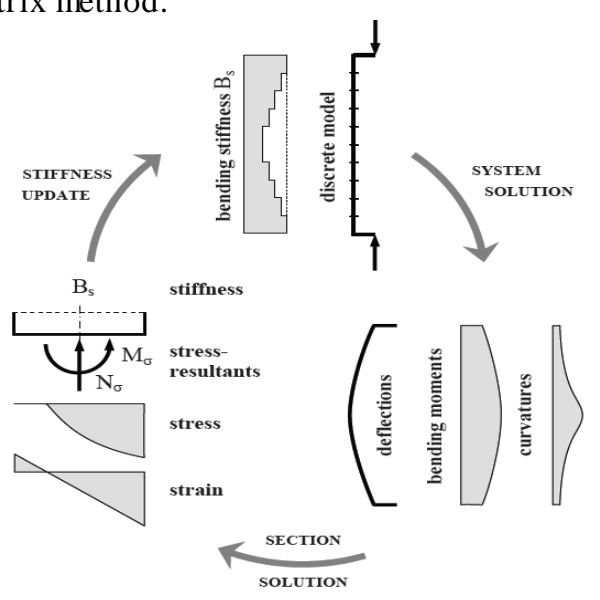

Figure 20: Iterative scheme of the evaluation procedure (Vassilev et al. 2009).

The expression for the compressive resultant becomes thus in the case of rectangular sections:

$N_{\sigma}=\frac{b}{K} \int_{s_{\mathrm{n}}-R t / 2}^{s_{0}+K t / 2} \sigma d \varepsilon=P$

Where, $\mathrm{t}, \mathrm{b}=$ width and depth of the section, $\mathrm{P}=$ applied load, $N_{\sigma}=$ resultant compressive axial force, $\sigma=$ stress, $K=$ curvature and $\varepsilon=$ strain.

The solution of Equation 24 yields the strain at the centroid $\varepsilon_{0}$ and determines unequivocally - along with the curvature $\kappa-$ the two relevant values of the current strain state: 
$\varepsilon_{\min }=\varepsilon_{0}-\frac{K t}{2} \quad ; \quad \varepsilon_{\max }=\varepsilon_{0}+\frac{K t}{2}$.

And finally, the formula for the updated value of the bending stiffness prior to the next iteration:

$B_{s}=\frac{b}{K^{3}} \int_{s_{\min }}^{s_{\max }} \sigma \varepsilon d \varepsilon-\frac{\varepsilon_{0}}{K^{2}} N_{\sigma}$

The results obtained in this numerical study presented below illustrate the potential of the approach. Figure 21 shows the two characteristic modes of failure independent of the load eccentricity. It varies in magnitude, but remains equal at both ends. The slenderness ratio is $\mathrm{h} / \mathrm{t}=$ 10 .

In the case of the figures on the left, the load acts with the small eccentricity $e=t / 8$. The cracking is primarily a consequence of the eccentricity amplification, induced by the secondorder deflections. The crack propagation is confined to the central part, while the boundary regions remain undamaged. The bearing capacity is reduced to $\Phi=0.597$ where $\Phi$ is the bearing reduction factor. The ultimate state is associated with material failure at the critical central section, at the stage when the maximum stress equals the material strength.

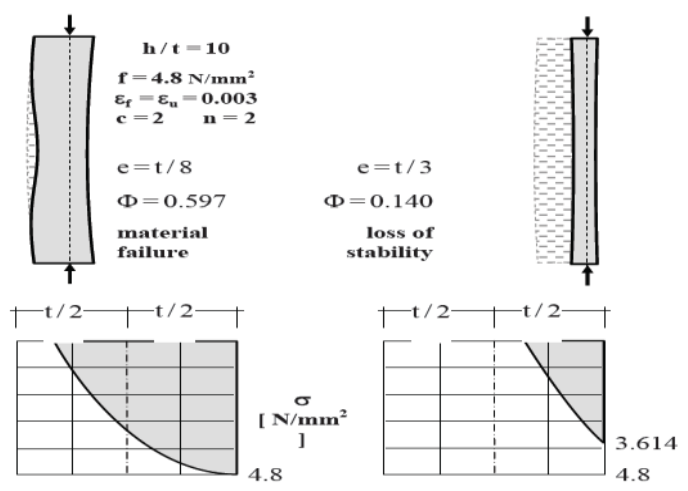

Figure 21: Deflection and damage at u ltimate limit state (Vassilev et al. 2009).

In the case on the figures on the right, the larger eccentricity of $\mathrm{e}=\mathrm{t} / 3$ leads a priori to cracking all over the height. The effective width of the interior sections is further reduced due to the second-order effects. At ultimate it is barely $1 / 3$ of the thickness at the critical section. The material strength is not reached as the system fails at $\Phi=$ 0.140 due to loss of stability. The plot in Figure 22 gives the calculated capacity versus the load eccentricity as well as the results of two series of tests with the eccentricity ratios $e / t=1 / 3$ and $e / t=$ 0.4 respectively. A good agreement between prediction and experiment can be registered in both cases. The numerical simulation indicates material failure as the cause for collapse in the case of the smaller eccentricity and loss of stability for the larger one.

The dashed lines on Figure 22 serve as reference by the evaluation of the results. They represent the material section capacity, based on two common simplified theories: stress-block and linear stress distribution. The prediction lies within the two limits as long as the eccentricity remains relatively small and material failure prevails. The capacity progressively drops below with the increasing eccentricity, when instability becomes dominating.

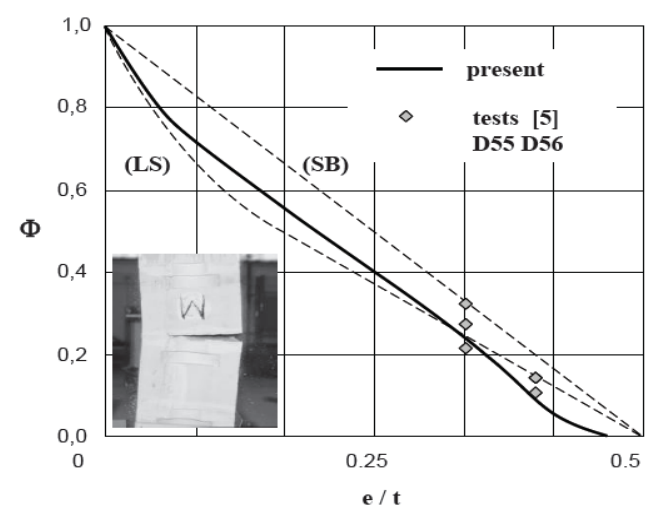

Figure 22: Capacity reduction factor versus load eccentricity; material section capacity (SB) based on stress block theory and (LS)-based on stress distribution (Vassilev et al. 2009).

\section{CONCLUSIONS}

The diverse combinations of slenderness ratio and load eccentricity used in the experimental program which provided the means for a comprehensive numerical analysis of the masonry wall. It must be noted that some difference with respect to the experimental results is unavoidable because of the influence of possible non-reported accidental eccentricities. It has been observed that an accurate description of tensile cracking and opening of mortar joints, by means of an appropriate interface element, is essential to obtain reliable results on the bucking failure of walls.

\section{REFERENCES}

[1] ACI-530 (2008). “ACI Manual of Concrete Practice." ACI 530.1-05/ASCE 6-05/TMS 602-05. A merican Concrete Institute.

[2] Chapman, J. C. and Slatford, J. (1957). "The Elastic Buckling of Brittle Columns." Inst. Civ. Eng., Vol. 107, No. 6.

[3] CEN (1995) - Eurocode 6: Design of masonry structures. ENV 1996-1-1:1995, CEN, Brussels, Belgium. 
[4] De Falco, A. and Lucchesi, M. (2007). "No Tension Beam-Columns with Bounded Compressive Strength and Deformability Undergoing Eccentric Vertical Loads." International Journal of Mechanical Sciences 49, p. 54-74.

[5] Hasan, S. S. and Hendry, A.W. (1976). "Effect of Slenderness and Eccentricity on the Compressive Strength of Walls." Proc. $4^{\text {th }}$ International Brick Masonry Conference (Brugge). Paper 4.d3.

[6] Lourenco, P. B. (1996). "Computational Strategies for Masonry Structures." $\mathrm{PhD}$ thesis, Delft University of Technology, Delft, The Netherlands.

[7] Mura, I. (2008). "Stability of Nonlinear Masonry Members Under Combined Load." Computers and Structures 86, p. 1579-1593.

[8] Page, A.W. (1978). "Finite Element Model for Masonry.” J. Struc. Div., ASCE, 104(8), p. $1267-1285$.

[9] Parland, H. (1982). "Basic Principles of the Structural Mechanics of Masonry: A Historical Review." Int. J. Mas. Constr., 2(2).

[10] Payne, D. C., Brooks, D. S. and Dved, G. (1990). "The Analysis and Design of Slender Brick Walls." Masonry International Journal, 4(2), p. 55-65.

[11] Pluijm, R. V (1992). "Material Properties of Masonry and its Components Under Tension and Shear." Proc. 6th Canadian Masonry Symposium, Eds. V.V. Neis, Saskatoon, Saskatchewan, Canada, p. 675-686.

[12] Sahlin, S. (1978). "Structural Masonry." Prentice-Hall Inc., New jersey, U. S. A.

[13] Sawko, F. and Towler, F. (1982). "Numerical Analys is of Walls and Piers with Different End Conditions." 6IBMAC. Ed. Laterconsult s.v.l., Rome, Italy.

[14] Yokel, F. Y. (1971). "Stability and Load Capacity of Members with no Tensile Strength.” J. Struct. Div. ASCE, 97(7), p. 1913-1926.

\section{ACKNOWLEDGEMENTS}

In completing this research, I would like to express my grateful appreciation and special thanks to Profess or Paulo Lourenco, Professor Enrico Garbin and PhD student Cristian Sandoval. A financial support from European Commission through Erasmus Mundus Scholarship is gratefully acknowledged. 